Asian J. Med. Biol. Res. 2018, 4 (2), 164-171; doi: 10.3329/ajmbr.v4i2.38251

\author{
Asian Journal of \\ Medical and Biological Research \\ ISSN 2411-4472 (Print) 2412-5571 (Online) \\ www.ebupress.com/journal/ajmbr
}

\title{
Article \\ Comparative effect of turmeric (Curcuma longa) and durba (Cynodon dactylon) on the healing of surgical wounds in cattle (Bos indicus)
}

\author{
Mohammad Abdullah-Al Mamun ${ }^{1 *}$, Nasrin Sultana Juyena², Md. Abu Hadi Noor Ali Khan ${ }^{3}$ and Md. Aminul \\ Islam $^{2}$ \\ ${ }^{1}$ Department of Livestock Services, Ministry of Fisheries and Livestock, Government of the People's Republic \\ of Bangladesh \\ ${ }^{2}$ Department of Surgery and Obstetrics, Faculty of Veterinary Science, Bangladesh Agricultural University, \\ Mymensingh-2202, Bangladesh \\ ${ }^{3}$ Department of Pathology, Faculty of Veterinary Science, Bangladesh Agricultural University, Mymensingh- \\ 2202, Bangladesh
}

*Corresponding author: Mohammad Abdullah-Al Mamun, Department of Livestock Services, Ministry of Fisheries and Livestock, Government of the People's Republic of Bangladesh. Phone: +8801761581235 ; Email: abdullahdvm@gmail.com

Received: 04 June 2018/Accepted: 24 June 2018/ Published: 30 June 2018

\begin{abstract}
Herbal preparations are used traditionally in wound management to promote wound healing process. In Bangladesh, there are limited researches on the use of herbal products to assist healing process. Therefore, this experiment was carried out to exploit turmeric (Curcuma longa) and durba (Cynodon dactylon) pastes in the treatment of surgical wounds in cattle and to study their healing effect on wound sutured with horizontal mattress using nylon. A total of 36 surgical wounds were made in six cattle. Tincture benzoin was used as control group. Follow-up information was recorded from day 0 to day 21 postoperatively. Some morphological characters such as swelling area of wound, elevation of sutured line from the skin surface, width of sutured area and contraction length per week were recorded to determine the healing process of the wounds. Bacteriological and histopathological studies were also performed. All wounds were closely monitored to observe any complications such as swelling, wound dehiscence, suture abscess, local infection and exudation etc. Results showed that Tr. Benzoin seal caused marked tissue reaction in wounds in comparison to turmeric and durba paste. Turmeric paste showed splendid results in the healing of the wounds produced in cattle. Durba paste also has wound healing activity but less effective than that of turmeric. This study could help veterinarians to consider herbal products especially turmeric for healing of wounds with minimum complications. Dissemination of these findings among the farmers may prevent skin degradation caused by the postoperative complications of the wound and thus improve the health status of livestock.
\end{abstract}

Keywords: wound healing; turmeric (Curcuma longa); durba (Cynodon dactylon); herbal paste; horizontal mattress

\section{Introduction}

Animals can get wounded at the farm, during transportation, or by getting strike against some hard objects, kicked by another animal or by goad and during different surgical interventions. Injury is directly related to poor quality of leather. The economic loss associated with leather defects is over one million taka per year in Bangladesh (Dey and Nooruddin, 1993). If not treated in proper time, a wound may lead to serious consequences (Harpal and Kuldip, 1993). The highest incidence among surgical affections in animals is wounds (Hossain et al., 1986). The skin or external wounds are more common in ruminants (Nooruddin and Dey, 1990). In Bangladesh most of the rural farmers have no facility for modern treatment for their 
livestock. In addition, many farmers cannot afford the cost of treatment. Under the circumstances, the rural farmers tend to incline towards traditional systems of animal treatment, which are relatively less expensive and available. So before taking the animal to the veterinarian, the owners try to treat their animals with various local remedies of which plant sources are mostly common. These remedies rather retard wound healing and ultimately quality of leather detoriated. It makes veterinarian complicated to handle wounds in most cases. There are many risk factors which cause postoperative wound complications. Immediate complications include hematoma, improper hemostasis and wound infection. Moreover, delayed complications include scar, eversion of the wound edges, stitch marks and wound necrosis (Gabrielli et al., 2001).

Wound management focuses on restoration of function and physical integrity with the minimum deformity and without infection (Adams et al., 2003). The aim of treating a wound is to either shorten the time required for healing or to minimize the undesired consequences (Myers et al., 1980). Various attempts have been taken to aid wound repair (Savanth and Shah, 1998). Now-a-days, different plant and herbal preparations has been used with tradition to promote wound healing process. The therapeutic efficacies of many indigenous plants, for various diseases have been described by traditional herbal medicine practitioners (Savanth and Mehta, 1996). Antimicrobial substances derived from plants have received considerable attention in recent years (Cutter, 2000; Shirazi et al., 2008; Jain et al., 2010). Moreover, efforts are being made to discover agents that can promote wound healing and thereby reduce the cost of hospitalization and save the patient from sufferings (Shukla et al., 1999). There are limited researches on the use of herbal product to assist healing process in Bangladesh (Islam, 2004). Therefore, this experiment was carried out with the aim to exploit the therapeutic effect of turmeric plant (Curcuma longa) and durba grass (Cynodon dactylon) pastes on surgical wound, to isolate the bacteria responsible for wound infection and to observe the histopathological changes of wound area during healing process.

\section{Materials and Methods}

The proposed research work was conducted during the period from November, 2011 to May, 2012 at Veterinary Teaching Hospital, Bangladesh Agricultural University (BAU Vet. Clinic), Mymensingh. The bacteriological and histopathological experiments of this research were performed at the Department of Pathology, Faculty of Veterinary Science, Bangladesh Agricultural University.

\subsection{Experimental animals}

Six apparently healthy cattle (Bos indicus) were used for this experiment. The body weight of the animals ranged from 80 to $120 \mathrm{Kg}$ and age ranged from 1-3 years. All of the experimental cattle were dewormed with albendazole (Almex ${ }^{\circledR}$, Square Pharmaceuticals) before starting the experiment.

\subsection{Experimental design}

A total of thirty six surgical wounds were made on the skin of six cattle. Cattle were divided into three groups with two animals in each group (Table 1).

Group-A: Fresh turmeric paste was applied locally daily to six surgical wounds made in each animal. These animals were maintained carefully so as to avoid interference with granulation tissue formation.

Group-B: Fresh paste of the leaves of durba was applied to six surgical wounds made in each animal. The treatment schedule was same as in Group-A.

Group-C: This group was kept as control. In this group benzoin seal was applied to six surgical wounds made in each animal. Benzoin consists of $10 \%$ benzoin, $90 \%$ alcohol with aloes, storax and Tolu balsam. It is a safe, natural substance to increase tackiness, therefore, used a 'medical varnish', forming a sealing 'film' over raw tissue to protect wounds from ingress of bacteria (Falkner-Heylings, 2011).

All wounds were closed with horizontal mattress pattern using nylon to mitigate the suture effects on wound healing. Similarly, antibiotic, antihistaminic or anti-inflammatory drug were avoided to mitigate their effects on healing process. Follow-up information was obtained since day of surgical operation up to day 21 after surgery. Some morphological characters such as swelling area of wound, elevation of sutured line from the skin surface, width of sutured area were recorded to determine the healing of the wounds. Elevation of sutured line was recorded during suture removal after 7 days of surgery. Width of sutured area was measured from the day of surgical intervention day $0\left(D_{0}\right)$, day $3\left(D_{3}\right)$, day $7\left(D_{7}\right)$, day $14\left(D_{14}\right)$, day $21\left(D_{21}\right)$ to determine wound contraction length. For bacteriological study, swabs were collected from all treatment groups at $\mathrm{D}_{1}, \mathrm{D}_{2}$ and $\mathrm{D}_{3}$. Tissue samples were collected from all treatment groups at $\mathrm{D}_{1}, \mathrm{D}_{3}$ and $\mathrm{D}_{7}$ for histopathological study. 


\subsection{Preparation of the herbal paste}

The fresh turmeric roots were collected from Bangladesh Agricultural University market and leaves of durba from Bangladesh Agricultural University Agronomy Field Station. The green leaves of durba were properly cleansed with water and taken in a mortar and grinded thoroughly with a pestle and the prepared paste was directly applied on wound. Similarly, turmeric paste was prepared from turmeric roots.

\subsection{Surgical technique}

Surgical wound was made by giving a vertical incision in the flank region (Figure 1a), each was of $5 \mathrm{~cm}$ length and $0.5 \mathrm{~cm}$ depth after following routine surgical procedure and the wound was closed with horizontal mattress using nylon (Figure 1b). After suturing durba paste, turmeric paste and benzoin seal were applied onto the sutured area of selected groups (Figure 2a, 2b and 2c). Sutures were removed at day 7 of post operation. Three wounds were made at a time in one side and similar operation was done in another lateral side at least after 15 days of previous incision. Incision was not given in same place of previous incision.

\subsection{Observation of wounds}

Slide calipers were used to measure swelling area $(\mathrm{mm})$, elevation of suture line $(\mathrm{mm})$ and width of the cutting edge of the sutured wound $(\mathrm{mm})$. A wound was assumed healed up when cicatrisation and pigmentation was found. Healing score was categorized as: 1. Excellent-characterized by no inflammation, no exudation, no infection, no dehiscence, gradual decreasing of width of cutting edge; 2. Good- characterized by minimum inflammation with minimum exudation, no dehiscence, gradual decreasing of width of cutting edge and 3. Faircharacterized by marked inflammation, presence of infection and exudation. All wounds were closely monitored to observe any complication such as swelling $(\mathrm{mm})$, wound dehiscence, suture abscess, local infection and exudation.

\subsection{Bacteriological study}

\subsubsection{Collection and culture of samples}

All of the bacteriological samples were collected aseptically from the wounds of cattle by using sterile cotton buds and promptly transferred into screwed capped test tubes containing nutrient broth. The collected samples were incubated in nutrient broth at $37^{\circ} \mathrm{C}$ for overnight. Then the samples were inoculated in nutrient agar by streak plate method and further incubated at $37^{\circ} \mathrm{C}$ for overnight to promote growth of bacteria to observe the cultural characteristics.

\subsubsection{Staining methods}

Gram's staining method was performed to study the morphological and staining characteristics of bacteria and to provide information about the presumptive bacterial identification.

\subsection{Biopsy and histopathology}

The biopsies containing dermis and epidermis $(1.5 \mathrm{~cm} \times 1 \mathrm{~cm})$ were collected from the wound areas of each experimental animal on the 1st, 3rd and 7th days after wounding using standard surgical procedure. The samples were fixed in $10 \%$ buffered neutral formalin solution more than seven days for histopathology. Histopathological slides were prepared according to the method of Luna (1968). The slides were stained with routine hematoxylin and eosin staining and examined under compound light microscope to evaluate tissue reaction differences between control and experimental group.

\subsection{Statistical analysis}

All data were presented as mean \pm SEM. To compare data among groups, one way ANOVA (Analysis of Variance) factor analysis was performed. The data obtained in the present investigation were analyzed with SAS 12.5 software. Probability $\mathrm{P}<0.5 \%$ was considered statistically significant.

\section{Results}

\subsection{Morphological changes in sutured wound}

Swelled area and elevation of suture line and contraction length were recorded in different groups are shown in Table 2. Among three groups, more swelled area was observed in wounds of control group. The swelling (12.65 $\pm 0.43 \mathrm{~mm}$ ) was significantly $(\mathrm{P}<0.05)$ higher in Group $\mathrm{C}$. Treatment with turmeric paste and durba paste results the swelling area $11.64 \pm 0.43 \mathrm{~mm}$ and $11.74 \pm 0.43 \mathrm{~mm}$ respectively. In this study, suture bite was $0.5 \mathrm{~mm}$ followed in all sutured wounds. We found that elevation of suture area varied significantly $(\mathrm{p}<0.05)$ with 
treatment. Elevation of sutured line was higher $(3.62 \pm 0.20 \mathrm{~mm})$ in wounds treated with tincture benzoin and lower $(2.52 \pm 0.20 \mathrm{~mm})$ in wounds treated with turmeric paste (Table 2). Higher swelled area and elevated suture line indicates presence of more inflammation in wounds treated with tincture benzoin.

All values of width of sutured area of three groups increased up to day 3 and then decreased gradually in all wounds irrespective of treatments (Table 3). Wounds treated with durba paste had higher diameter of sutured area in comparison to that of wound treated with turmeric paste and tincture benzoin up to day 3 and variation was statistically significant $(\mathrm{p}<0.05)$. Later width of sutured line gradually decreased and variation was insignificant up to day 21.

\subsection{Microbiological study}

Bacterial colonies were present in culture of all samples collected from durba grass group at different times (Figure 3a), whereas, bacterial colonies were present in culture of samples of benzoin seal and turmeric groups at day 1. Gram's staining confirmed the presence of Staphylococcus spp. (Figure 3b). The species of Staphylococcus spp. isolated from the samples showed greywhite to yellowish colonies on nutrient agar.

\subsection{Histopathological changes}

Histological study of biopsies taken from various treatment groups were focused on the presence of reactive cells as an indication of inflammation. The infiltration of reactive cells including neutrophils, macrophages, and lymphocytes were present all samples of three groups collected at $D_{1}$, which indicated presence of inflammation as a normal tissue response to suture and tissue handling. Reactive cells decreased gradually in wounds of durba and turmeric groups. Moreover, proliferation of fibrous connective tissue was observed markedly in wounds of turmeric group at $D_{3}$. In contrast, massive infiltration of reactive cells was observed under keratinized layer of epidermis in samples of control group collected at $D_{3}$. All samples of three groups collected at $D_{7}$ showed reduced number of reactive cells along with newly formed connective tissue (Figure 4a, 4b and 4c). An interesting finding was observed in samples of turmeric group at $\mathrm{D}_{7}$, where newly formed keratinized layer of epidermis was found under the scab infiltrated with reactive cells (Figure 4b). This histological finding indicated sloughing of strangulated cutting edge after healing of suture line when wounds closed with horizontal mattress. This typical histological finding was absent in wounds of durba and control groups at $\mathrm{D}_{7}$ postoperatively indicated comparatively delay healing of these wounds (Figure 4a and 4c).

Table 1. The experimental protocol.

\begin{tabular}{lllll}
\hline Groups & Materials for treatment & Form of Materials & No. of animals & No. of wounds \\
\hline A & Turmeric & Paste & 2 & 12 \\
B & Durba & Paste & 2 & 12 \\
C & Tincture benzoin co. & Solution & 2 & 12 \\
\hline
\end{tabular}

Table 2. Different parameters of wounds treated with durba, turmeric paste and benzoin seal.

\begin{tabular}{llllll}
\hline Groups & $\begin{array}{l}\text { Swelling of } \\
\text { suturing area }\end{array}$ & $\begin{array}{l}\text { Elevation of } \\
\text { sutured line } \\
(\mathbf{m m})\end{array}$ & $\begin{array}{l}\text { Average } \\
\text { contraction } \\
\text { Length }\end{array}$ & Observation & $\begin{array}{c}\text { Healing } \\
\text { score }\end{array}$ \\
\hline Durba & $11.74 \pm 0.43^{\mathrm{a}}$ & $3.0 \pm 0.20^{\mathrm{a}}$ & $1.42 \pm 0.20$ & $\begin{array}{l}\text { Moist suture surface, liking present, } \\
\text { infection and myiasis (1), delay } \\
\text { healing }\end{array}$ & $\begin{array}{l}\text { Fair (5) } \\
\text { Good (7) }\end{array}$ \\
Turmeric & $11.64 \pm 0.43^{\mathrm{a}}$ & $2.52 \pm 0.20^{\mathrm{a}}$ & $1.62 \pm 0.20$ & $\begin{array}{l}\text { Dry sutured surface, no } \\
\text { inflammation, early healing from } \mathrm{D}_{3}\end{array}$ & Excellent \\
Benzoin seal & $12.65 \pm 0.43^{\mathrm{b}}$ & $3.62 \pm 0.20^{\mathrm{b}}$ & $1.67 \pm 0.20$ & Moist sutured surface, delay healing Good & Ged \\
\hline
\end{tabular}

$\mathrm{a}, \mathrm{b}$ indicate significant $(\mathrm{p}<0.05)$ difference in groups; Mean $\pm \mathrm{SEM}$

Table 3. Width (mm) of sutured area of wounds treated with durba, turmeric paste and benzoin seal.

\begin{tabular}{llllll}
\hline Groups & $\mathbf{D}_{\mathbf{0}}$ & $\mathbf{D}_{\mathbf{3}}$ & $\mathbf{D}_{\mathbf{7}}$ & $\mathbf{D}_{\mathbf{1 4}}$ & $\mathbf{D}_{\mathbf{2 1}}$ \\
\hline Durba & $8.42 \pm 0.30^{\mathrm{a}}$ & $9.2 \pm 0.33^{\mathrm{a}}$ & $7.33 \pm 0.26$ & $5.92 \pm 0.27$ & $4.2 \pm 0.22$ \\
Turmeric & $6.62 \pm 0.30^{\mathrm{b}}$ & $7.37 \pm 0.33^{\mathrm{b}}$ & $7.33 \pm 0.26$ & $5.70 \pm 0.27$ & $4.2 \pm 0.22$ \\
Benzoin seal & $6.92 \pm 0.30^{\mathrm{b}}$ & $8.08 \pm 0.33^{\mathrm{b}}$ & $7.75 \pm 0.26$ & $6.08 \pm 0.27$ & $4.0 \pm 0.22$ \\
\hline
\end{tabular}

$\mathrm{a}, \mathrm{b}$ indicate significant $(\mathrm{p}<0.05)$ difference in groups; Mean \pm SEM 

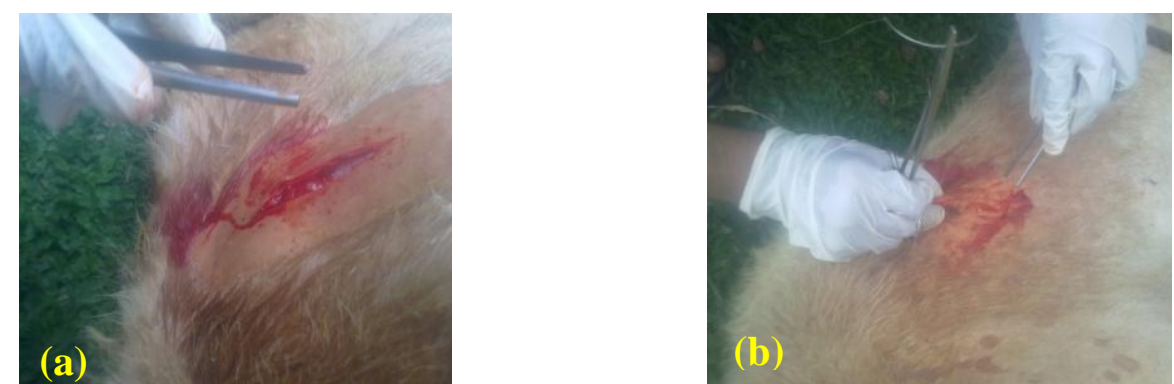

Figure 1. Fresh surgical wound just after incision (a) and suturing of incised wound as horizontal mattress pattern (b).
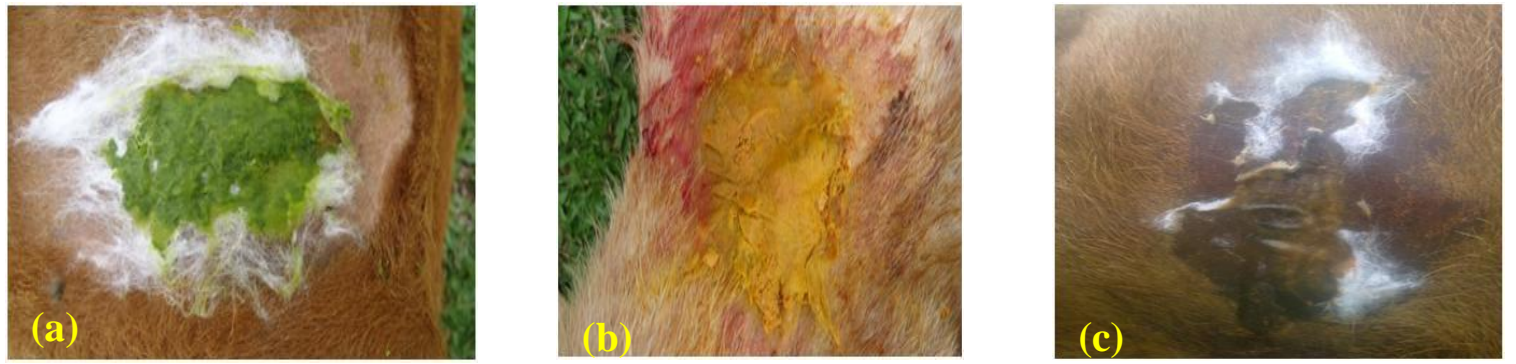

Figure 2. Application of durba paste (a), turmeric paste (b) and benzoin (c) on sutured wound.
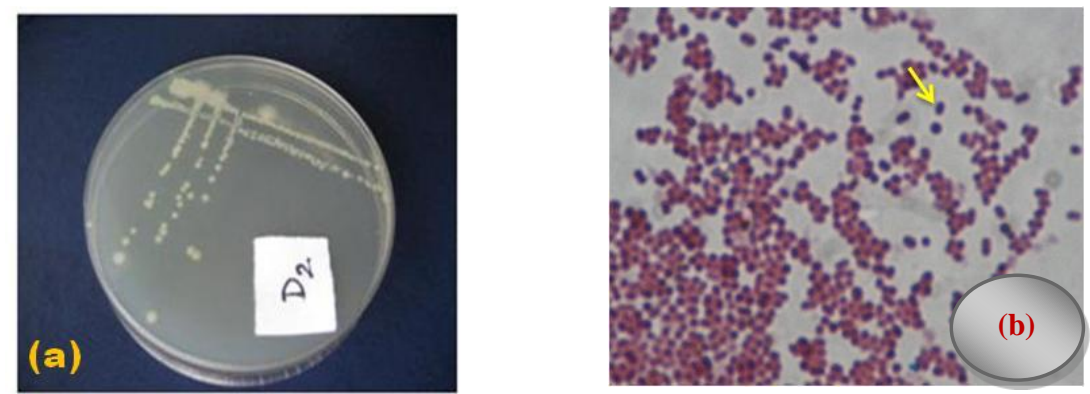

Figure 3. Presence of bacterial colony in primary culture of nutrient agar observed in samples collected from groups durba paste (a) and The spherical shaped bacteria (arrow) arranged in culture (Staphylococcus spp.) was isolated from dermal wound (b).
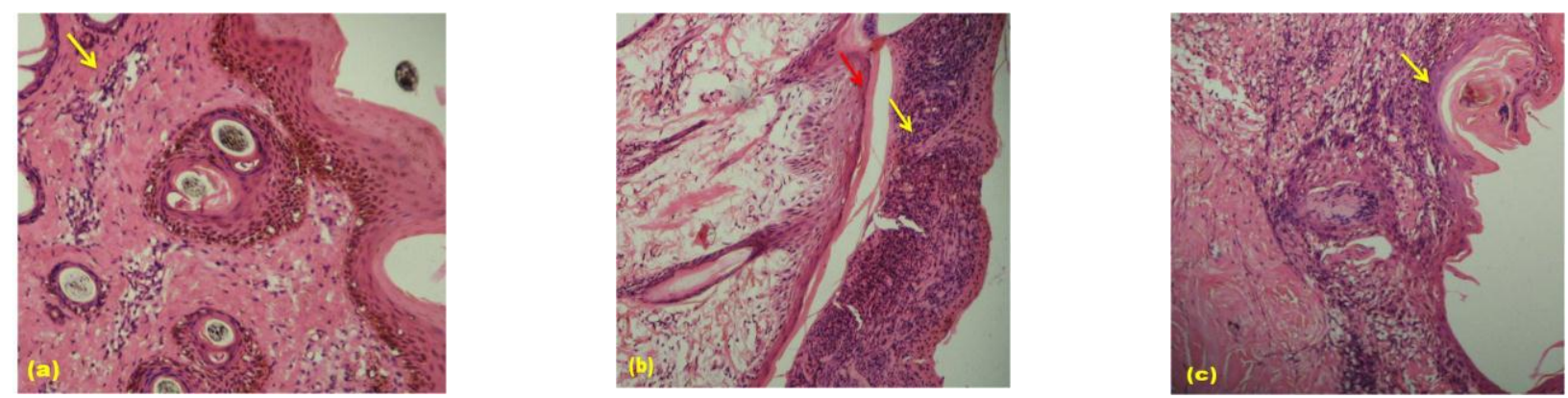

Figure 4. Histopathological changes in wounds of durba (a), turmeric (b) and control (c) groups at $\mathrm{D}_{7}$. In turmeric group (b) newly formed keratinized layer with new cells were present (red arrow). Yellow arrow shows reactive cells.

\subsection{Other observations}

In our study, all wounds treated with durba paste showed marked inflammation with moist sutured area at day 7 when sutures were removed. Moreover, infection, tissue erosion and myiasis were present in one wound treated with durba paste. According to healing score scale, fair to good healing was observed in wounds treated with durba paste. In contrast, all sutured wounds treated with turmeric paste maintained excellent healing score (Table 3.1). There was dry sutured surface without any inflammation when sutures were removed from wounds 
of turmeric group. Moreover, early healing and sloughing of cutting edges were observed from $\mathrm{D}_{7}$ to $\mathrm{D}_{14}$. Comparatively moist suture surface and delay healing were observed in wounds of durba and control groups and sloughing of cutting edges was found in between $\mathrm{D}_{14}-\mathrm{D}_{21}$. No dehiscence was observed in any wound of three groups.

\section{Discussion}

Results showed that width of sutured line markedly decreased from day 7 (Table 3) in all wounds irrespective of treatment. This result supports the hypothesis, which states that wound contraction depends on the myofibroblast located at the periphery of the wound, its connection to components of the extra cellular matrix and myofibroblast proliferation (Rohrich, 1990).

Among three groups, higher swelled area and elevation of suture line were observed in wounds of control group where wounds treated with tincture benzoin in comparison to that of other two groups. This result hypothesizes that tincture benzoin cause marked tissue reaction in wounds. Histological findings of this experiment confirm this hypothesis. We found marked infiltration of reactive cells in samples collected from benzoin group from $\mathrm{D}_{1}$ to $\mathrm{D}_{3}$. Moreover, proliferation of fibrous connective tissue was markedly observed in wounds of turmeric group at $\mathrm{D}_{3}$. This result indicates stimulatory effect of turmeric in wound healing and is in agreement with the finding of Sidhu et al. (1999). They reported that curcumin improves reepitheliazation and migration of cells such as myofibroblasts, fibroblasts, and macrophages, necessary for healing at the wound site.

The sloughing off cutting edges and thereafter, prominent scar was observed earlier within 7-14 days postoperatively when wounds were treated with turmeric paste. Presence of new keratinized tissue under a previous scab in histological samples collected from wounds treated with turmeric confirms this gross finding. There are many studies reported the anti inflammatory action of turmeric and their beneficial roles in promoting healing process. Curcumin, a yellow pigment from turmeric (Curcuma longa) reduces inflammation. Curcumin inhibits pain and inflammation and supports homeostasis by selectively inhibiting the arachidonic acid cascade through both the lipoxygenase and cyclooxygenase (COX) pathways (Ammon et al., 1993; Majeed, 1995). Some studies also reports that curcumin selectively inhibits synthesis of inflammatory prostaglandin thromboxane without affecting prostacyclin synthesis. Like turmeric, the aqueous extract of durba is said to possess significant wound healing activity evidenced by a decrease in the period of epithelialization, increase in the rate of wound contraction and tensile strength (Garg et al., 2009). Durba grass (Cyanodon dactylon) is a valuable herbal medicine and used as first aid for minor injuries (Oudhia, 1999). Whereas, several report show hat Tr. Benzoin can cause dermatitis (James et al., 1984; Scardamaglia et al., 2000) and promotes the growth of granulation tissue (Falkner-Heylings, 2011).

Bacteriological study showed that bacterial infection occur in wounds in the form of biofilms, which are complex communities of aggregated bacteria embedded in a self-secreted extracellular polysaccharide matrix Staphylococcus aureus (S. aureus), Pseudomonas aeruginosa (P. aeruginosa), and $\beta$-hemolytic Streptococci are common bacteria in infected and clinically non-infected wounds (Edwards and Harding, 2004). Kaleeswaran et $a l$. (2010) investigated the antibacterial activity of durba against gram positive and gram negative bacteria and they found that E. coli, B. subtilis, S. aureus and A. hydrophila were more susceptible in the ethanolic extract and no result was found in aqueous extract of durba.

Histopathological study revealed the infiltration of reactive cells including neutrophils, macrophages and lymphocytes in all groups at $\mathrm{D}_{1}$. This might be resulted from the inflammatory response as a foreign body reaction due to traumatic tissue handling and suture placement (Runk et al., 1999).

There are many risk factors for the development of postoperative wound complications in veterinary medicine. Among wound complications scar formation may be due to improper suturing with excess tension or to lack of eversion of the edges, stitch marks and wound necrosis (Gabrielli, 2000). In this study, nylon is used as a suture material in all wounds to mitigate the suture effect on wound healing. Monofilament nylon has the advantages of superlative strength, pliability, being no capillary and inert, and it produces the least amount of swelling response in wound (Varma et al., 1987). In addition, nylon suture is the most resistant to bacterial adherence (Denardo et al., 1996).

In this experiment, turmeric paste showed excellent healing score without any postoperative complication and it can be summarized that turmeric play a beneficial role in surgical wound healing. However, this study could help veterinarians to consider herbal product especially turmeric as a good healing material with minimum complications.

Investigation of wound healing process by using the active principles responsible for healing will add more insight of healing mechanism. As turmeric showed a good result in proper healing and controlling of bacteria in 
wounds, future study should be directed to explore active component responsible for its effects on bacteria and wound healing.

\section{Conclusions}

This study concludes that tincture benzoin seal causes marked tissue reaction in wounds. Turmeric paste and benzoin seal can control infection in wounds. Turmeric paste showed splendid results in the healing of the wounds produced in cattle. Durba paste showed wound healing activity but less effective than that of turmeric. Dissemination of these findings among the farmers may prevent skin degradation caused by the postoperative complication of the wound and thus improve the health status of livestock.

\section{Conflict of interest}

None to declare.

\section{References}

Adams B, AM Jamshaid, A David, MD Wrone and MD Murad Alam, 2003. In: Techniques for cutaneous sutured closures: Variants and indications. pp. 311-314.

Ammon HP, H Safayhi, T Mack and J Sabieraj, 1993. Mechanism of anti-inflammatory actions of curcumin and boswellic acids. J. Ethnopharamcology., 38: 113-119.

Cutter CN, 2000. Antimicrobial effect of herb extracts against E. coli O157:H7, Listeria monocytogenes and Salmonella typhimurium associated with beef. J. Food. Protect., 63: 601-607.

Denardo GA, NO Brownn, BS Trenka and S Niarrettia, 1996. Cotipalisoii of sexven ditterent slituire iliaterials in the telilne oral cavits. Joortia Lof Atxituto Assoclatiotion, 32: 164-172.

Dey AS and M Nooruddin, 1993. Economic impact of leather defect in Bangladesh. Bang. J. Train. and Dev., 6: 27-38.

Edwards R and Harding KG, 2004. Bacteria and wound healing. Curr. Opin. Infect. Dis., 17: 91-96.

Falkner-Heylings, 2011. Compound Tincture of Benzoin: Alliance Professional Development Programme.

Gabrielli F, C Potenza, P Puddu, F Sera, C Masini and D Abeni, 2001. Suture materials and other factors associated with tissue reactivity, infection, and wound dehiscence among plastic surgery outpatients. Plastic \& Reconstructive Surgery, 107: 38-45.

Garg VK, RL Khosa and SK Paliwal, 2009. Wound healing activity of aqueous extract of cynodon dactylon. Pharmacologyonline, 1: 1246-1255.

Harpal S and S Kuldip, 1993. Wound healing and tissue repair. In: Ruminant Surgery. Ist edn. Edited by R. A. S. Tyagi and J. Singh. CDS publishers and Distributors, Delhi. pp. 58-71.

Hossain MA, M Shahidullah and MA Ali, 1986. A report on surgical diseases and reproductive disorders recorded at the Veterinary Hospital of Bangladesh Agricultural University, Mymensingh. Bang. Vet. J., 20: $1-5$.

Islam SA, 2004. Comparison of the effect of certain plant extracts and antibiotic on artificially produced wound in Black Bengal goats. M.S. Thesis, Department of Surgery and Obstetrics, Bangladesh Agricultural University, Mymensingh.

Jain P, D Bansal, P Bhasin and Anjali, 2010. activity and phytochemical screening of five wild plants against Escherichia coli, Bacillus subtilis and Staphylococcus aureus. Journal of Pharmacy Research, 3: 1260- 1262.

James WD, SW White and B Yanklowitz, 1984. Allergic contact dermatitis to compound tincture of benzoin. J. Am. Acad. Dermatol., 11: 847-50.

Kaleeswaran B, S Ilavenil and Ravinkumar, 2010. Screening of phytochemical properties and antibacterial activity of Cynodon dactylon L. International Journal of Current Research, 3: 83-88.

Luna LGHT, 1968. Manual of histological technique. 3rd edn. McGraw/ Hall Book Company.

Majeed M, 1995. Curcuminoids: antioxidant nutrients. Piscataway, NJ: Nutriscience Pubs., Inc.

Myers KA, RD Marshal and J Friedin, 1980. Principles of Pathology in Surgery, 1st edn. Blackwell Scientific Publications: London. pp. 58-82.

Nooruddin M and AS Dey, 1990. Further study on the prevalence of skin disease in domestic ruminants in Bangladesh. Bang. Vet., 4: 5-9.

Oudhia P, 1999. Medicinal weeds in rice fields of Chhattisgarh (India). Int. Rice Res. Notes, 24: 40.

Rohrich RJ, 1990. Wound healing and closure, abnormal scars, envenomation and extravasation injuries. In: Plastic Surgery. Edited by J. G. McCarthy. W. B. Saunders, Philadelphia. pp. 2-17.

Runk A, SW Allen and EA Mahaffey, 1999. Tissue reactivity to poliglecaprone 25 in the feline linea alba. Vet. Surg., 28: 466-471. 
Savanth SS and N Mehta, 1996. In: Savanth SS, Shah RA, Gore D. (Eds.) Text book and atlas of dermatosurgery and cosmetology, 1st edn. ASCAD: Mumbai. pp. 50-61.

Savanth SS and RA Shah, 1998. In: Savant SS, Shah RA, Gore D. (Eds.) Text book and atlas of Dermatology and Cosmetology, 1st edn. ASCAD: Mumbai. pp.12-17

Scardamaglia L, R Nixon and J Fewings, 2003. Compound tincture of benzoin: a common contact allergen? Australas. J. Dermatol., 44: 180-185.

Shirazi MH, R Ranjbar, S Eshraghi, G Amin, MS Nouri and N Bazzaz, 2008. Inhibitory Effects of Sage Extract on the Growth of Enteric Bacteria. Pakistan Journal of Biological Sciences, 11: 487-489.

Shukla A, AM Rasik and BN Dhawan, 1999a. Asiaticoside-induced elevation of antioxidant levels in healing wounds. Phytother. Res. 13: 50-54.

Sidhu GS, H Mani and JP Gaddipati, 1999. Curcumin enhances wound healing in streptozotocin induced diabetic rats and genetically diabetic mice. Wound-Repair-and-Regeneration, 7: 362-374.

Varma S, LW Johnson, HL Ferguson and WV Lumb, 1981. Tissue reaction to suture materials in infected surgical wounds a histopathologic evaluation. Am. J. Vet. Res., 42: 563-570 